\title{
Route to Benzimidazol-2-ones via Decarbonylative Ring Contraction of Quinoxalinediones: Application to the Synthesis of Flibanserin, A Drug for Treating Hypoactive Sexual Desire Disorder in Women and Marine Natural Product Hunanamycin Analogue
}

\author{
Rahul D. Shingare, ${ }^{\dagger,}$ Akshay S. Kulkarni, ${ }^{\dagger}$ Revannath L. Sutar, ${ }^{\dagger}$ and D. Srinivasa Reddy ${ }^{*},, \ddagger \odot$ \\ ${ }^{\dagger}$ Division of Organic Chemistry, CSIR-National Chemical Laboratory, Dr. Homi Bhabha Road, Pune 411008, India \\ ${ }^{\ddagger}$ Academy of Scientific and Innovative Research (AcSIR), New Delhi 110 025, India
}

Supporting Information
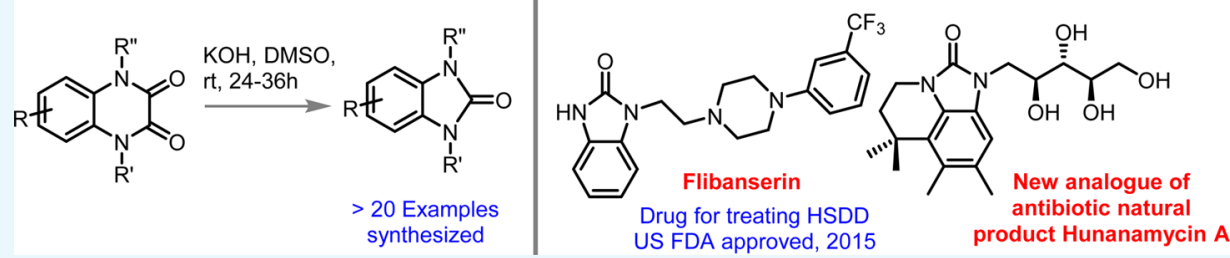

ABSTRACT: A simple and practical method to access a variety of benzimidazol-2-ones is reported here. A series of $N$-alkylsubstituted benzimidazol-2-ones were synthesized by decarbonylative ring contraction starting from corresponding quinoxalinediones for the first time. The utility of the method has been demonstrated by synthesizing recently approved controversial drug flibanserin (Addyi) and a urea analogue of marine antibiotic natural product hunanamycin-A.

\section{INTRODUCTION}

Benzimidazol-2-ones 1 are an important class of heterocycles and a privileged scaffold in medicinal chemistry. They consist of cyclic urea fused with the aromatic backbone, which can potentially interact in a biological system by various noncovalent interactions such as hydrogen bonding and $\pi$ stacking. Benzimidazolone derivatives exhibit a wide range of biological activities, and they are useful in treating various diseases including cancer, type II diabetes, central nervous system disorders, pain management, and infectious disease. ${ }^{1}$ Selected compounds embedded with a benzimidazol-2-one moiety along with their use are captured in Figure 1. It is worth mentioning that oxatomide drug with a benzimidazol-2-one core was approved for marketing a few years ago. ${ }^{2 a}$ Very recently, US Food and Drug Administration approved a new drug called flibanserin for the treatment of hypoactive sexual desire disorder (HSDD) in females, which contains benzimidazol-2one motif. ${ }^{2 b}$

\section{RESULTS AND DISCUSSION}

Considering interesting biological activity and the importance of this scaffold, we sought to develop a new and efficient method for the preparation of benzimidazolones. Literature search revealed that most of the methods for the synthesis of a benzimidazol-2-one core rely on carbonylation of benzene-1,2diamines $\mathbf{2}$ or cyclization of appropriately substituted phenyl urea 3. The carbonylation reaction of benzene-1,2-diamines requires the use of phosgene, triphosgene, or carbonyl diimidazole. ${ }^{3}$ To avoid the use of such hazardous chemicals,
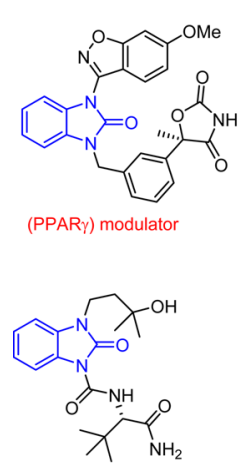

novel $\mathrm{CB}_{2}$ selective agonist

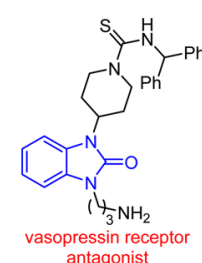

antagonist
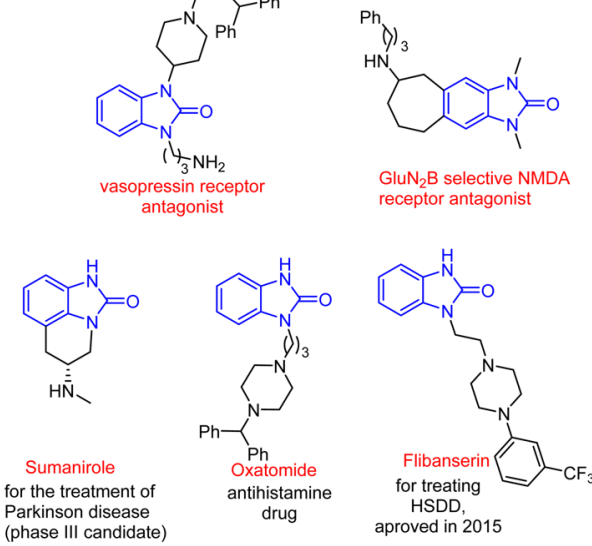

Figure 1. Examples of biologically important benzimidazolones.

alternative procedures using transition metals (palladium ${ }^{4}$ and copper ${ }^{5}$ )-catalyzed intramolecular 3 or intermolecular 4 cyclization or $\mathrm{C}-\mathrm{H}$ oxidation ${ }^{6}$ reactions were developed. Some of the interesting interconversions of heterocyclic rings for the synthesis of benzimidazol-2-ones are also reported. According to Zhou's work, aminomethylene benzimidazoles 5 and alkyl halide in the presence of a base produced

Received: June 19, 2017

Accepted: August 15, 2017

Published: August 29, 2017 
benzimidazolones. $^{7 \mathrm{a}}$ The Mamedov group synthesized highly functionalized $\mathrm{N}$-pyrrolylbenzimidazol-2-ones through the rearrangement of substituted quinoxalin-2(1H)-ones $6^{7 \mathrm{~b}}$ In this regard, it is noteworthy to highlight the efforts by Bolm and co-workers for the development of a mild method to access such heterocycles. ${ }^{8}$ Moreover, work on $\mathrm{N}$-arylated and $\mathrm{N}$ alkylated benzimidazol 2-ones is less explored. Here, we have developed a mild method for the decarbonylation of easily accessible quinoxalinediones ${ }^{9} 7$ to form benzimidazol-2-ones using potassium hydroxide $(\mathrm{KOH})$ in dimethyl sulfoxide (DMSO). To the best of our knowledge, this transformation has not been reported in the literature (Scheme 1).

Scheme 1. Selected Routes to Benzimidazol-2-ones and Our Work

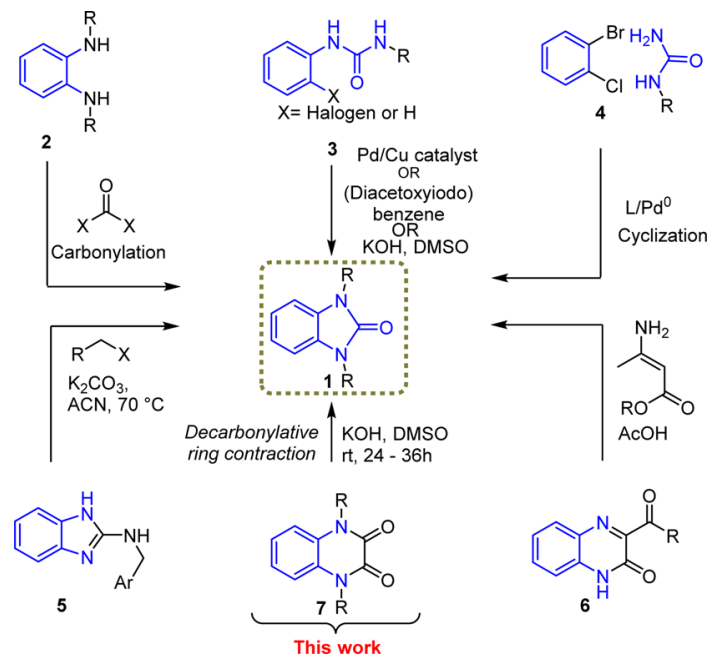

As part of one of the ongoing projects in our group, we were interested in the synthesis of tetracyclic $N$-heterocyclic carbenes ${ }^{10}$ from the corresponding tetracyclic compound $\mathbf{1 0}$ which in turn was readily prepared from quinoxalinedione through prenylation followed by Friedel-Crafts alkylation (Scheme 2). We have attempted hydrolysis of 1,1,10,10tetramethyl-1,2,3,8,9,10-hexahydropyrazino[1,2,3,4-mn][1,10]phenanthroline-5,6-dione 10 using $\mathrm{KOH}$ and DMSO at room temperature to have the corresponding diamine. Fortuitously, a new product was isolated from the reaction, which showed similar proton nuclear magnetic resonance spectrum with $\sim 0.3$

\section{Scheme 2. Unexpected Formation of Tetracyclic Urea} Derivative

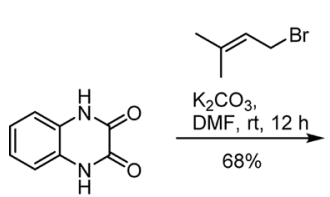

8

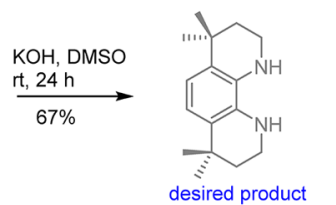

desired product
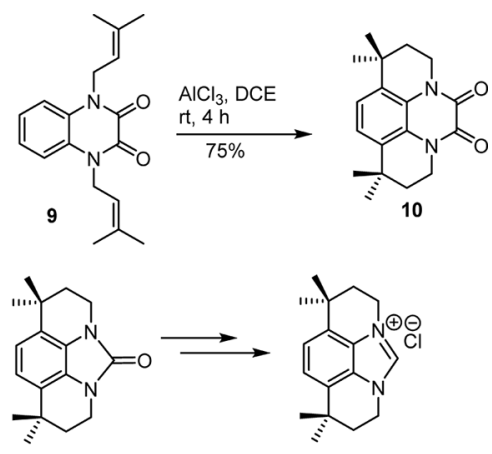
$10 \mathrm{a}$
isolated product
confirmed by ${ }^{13} \mathrm{C}$
NMR and Mass
Table 1. Optimization for Decarbonylative Ring Contraction

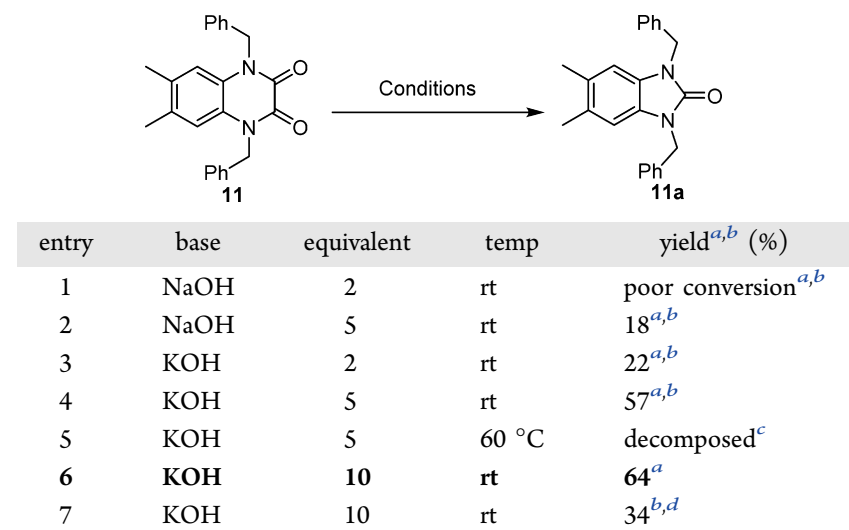

${ }^{a}$ Reaction tried on $50 \mathrm{mg}$ scale in DMSO solvent, stirred for $24 \mathrm{~h}$ and isolated yield. ${ }^{b}$ Starting material (SM) recovered. ${ }^{c}$ Stirred for $12 \mathrm{~h}$. ${ }^{d}$ Dimethylformamide (DMF) solvent.

ppm difference with respect to starting dicarbonyl compound 10, but carbon nuclear magnetic resonance $\left({ }^{13} \mathrm{C} N M R\right)$ spectrum showed a considerable difference in most of the peaks including the presence of one peak for carbonyl carbon at $\delta 152.6 \mathrm{ppm}$ (Figure 2). The assigned structure was further supported by high-resolution mass spectrometry analysis (271.1798) which corresponds to a ring-contracted product 10a. The structure of 10a was further confirmed by comparing its spectral data where it was synthesized differently. ${ }^{10}$ Having made this interesting observation, compound $\mathbf{1 1}$ was chosen for further optimization and subjected to various conditions listed in Table 1. By changing the base, equivalent, and temperature, we were settled with the optimized condition as 10 equiv of $\mathrm{KOH}$ in DMSO at room temperature. After optimization, we tested the scope of the method with different substrates and prepared several substituted quinoxalinediones. The results along with the yields of the isolated products are summarized in Table 2. Initially, we have subjected different $N$-alkylated 6,7dimethyl 1,4-dihydroquinoxaline-2,3-diones (compounds 1318) for the decarbonylative ring contraction and found that all of them are well-tolerated and gave good yields. To our surprise, attempts to afford the desired product in the case of $\mathrm{N}$-unsubstituted quinoxaline-2,3-diones (12 and 25) were unsuccessful. This may be due to the fact that secondary amides exist in their tautomeric form, that is, imidic acid, probably which hindered the hydrolysis step. Aromatic ring without any substitution also gave a good yield of products (compounds 19 and 20). Methoxy substitution on the aromatic ring (compounds 21-24) was also tolerated but obtained moderate yield along with the recovery of the starting material. We could not improve the yield by increasing the reaction time to $36 \mathrm{~h}$. Furthermore, to broaden the substrate scope, we have synthesized unsymmetrical $N, N$ di-substitution on the quinoxaline-2,3-dione core which is part of our antibacterial research interest. $^{11}$ All of these compounds with unsymmetrical substitution were subjected to previously optimized condition and resulted in better yields of the desired products (compounds 26-33). Almost in all cases, we have observed the formation $\sim 5-10 \%$ of the corresponding diamine (resulting from complete hydrolysis). As a direct application and to demonstrate the usefulness of the method developed, we decided to perform late-stage transformation on hunanamycin A 34, an antibiotic natural product derived from marine source, which contains a quinoxaline-2,3-dione core. ${ }^{12}$ Hunanamycin 


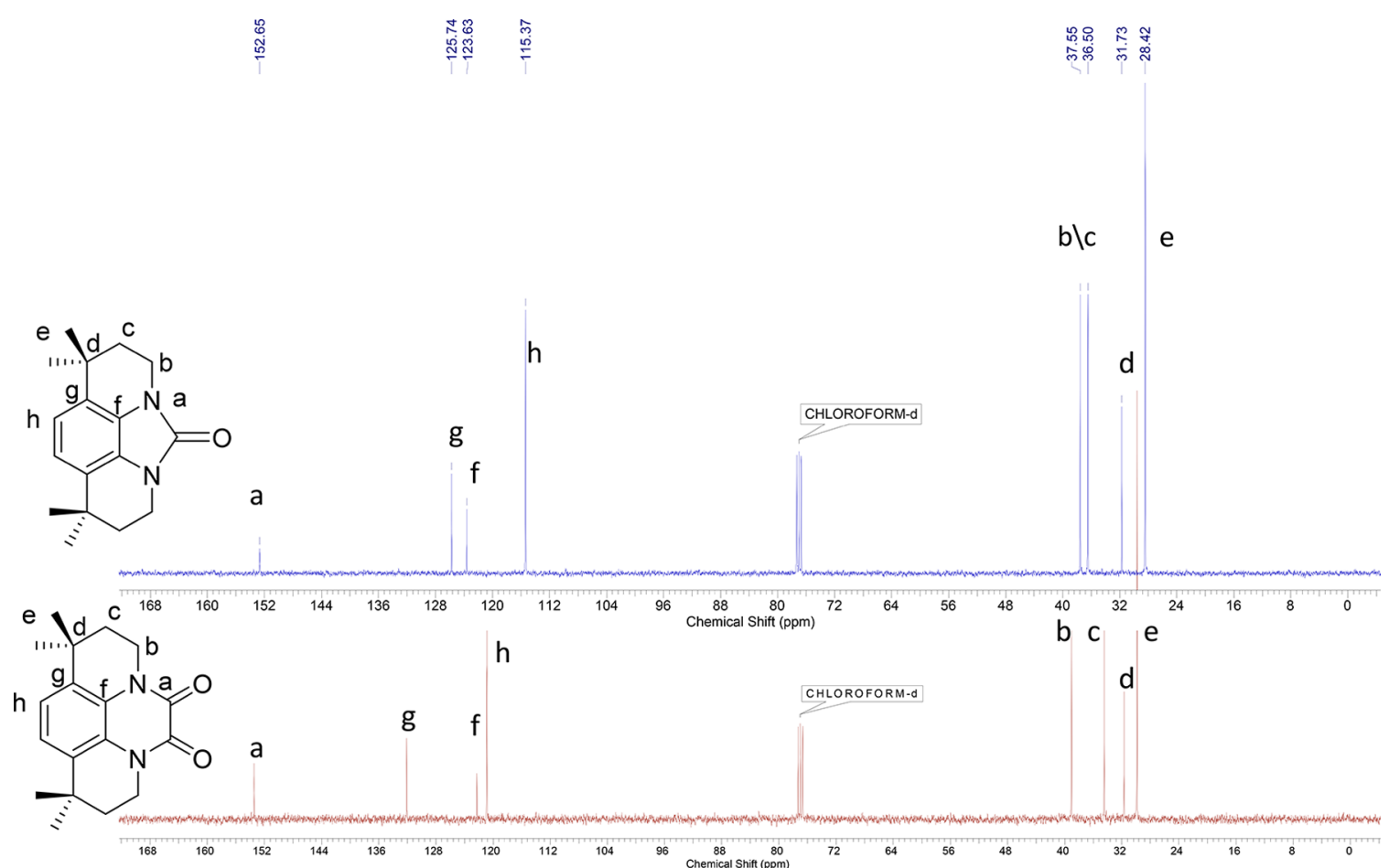

Figure $2 .{ }^{13} \mathrm{C}$ NMR spectrum of 10 and 10a.

Table 2. Scope of the Decarbonylative Ring Contraction To Access Benzimidazol-2-ones

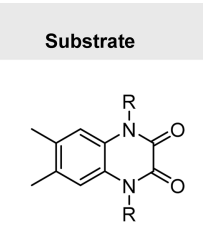

12; $\mathrm{R}=\mathrm{H}$ $\begin{array}{ll}\text { 13; } & R=\text { Methyl } \\ \text { 14: } & R=\text { Ethyl } \\ \text { 15; } & R=\text { Alyl }\end{array}$ 15; $R=$ Allyl 16: $R=$ Prenyl 17; $R=$ 3-Methylbutyl

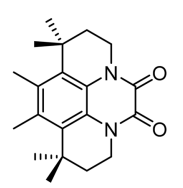

18

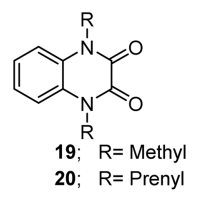

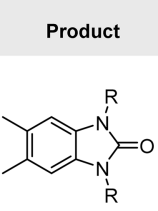

12a; $R=\mathrm{H}$ 13a; $R=$ Methyl 14a; $R=$ Ethyl 15a; $R=$ Allyl 16a; $R=$ Prenyl 17a; $R=3$-Methylbutyl
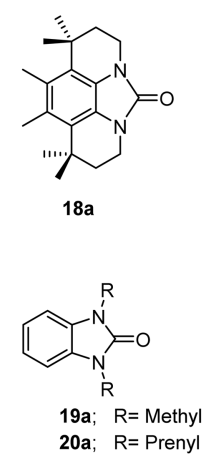

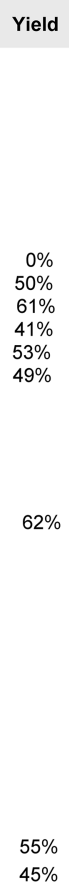

$45 \%$
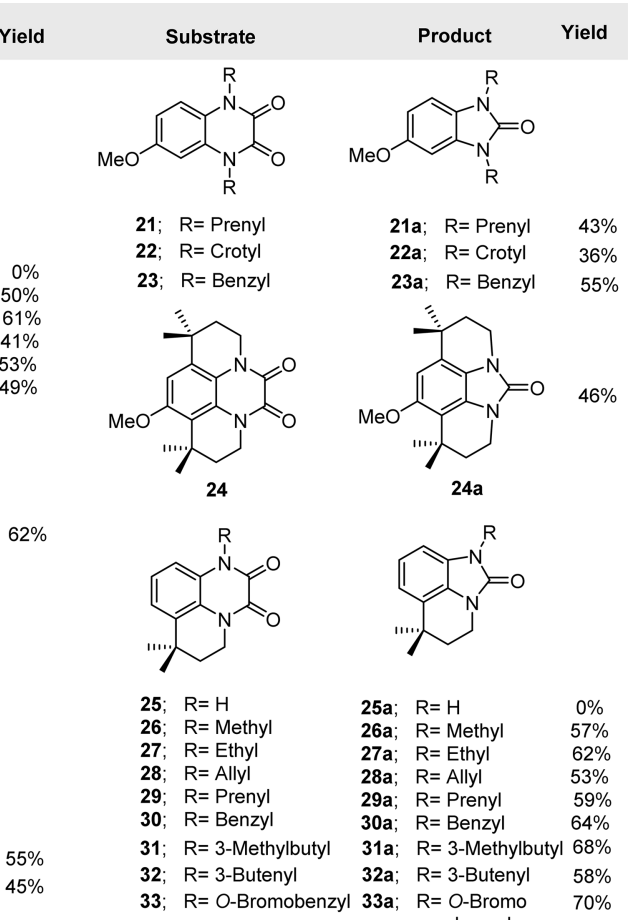
benzyl showed potent antibiotic activity against Salmonella enterica which causes food poisoning. ${ }^{13}$ Pleasingly, the reaction went smoothly to furnish benzimidazol-2-one 35 , a new analogue of hunanamycin A in one step. All of the spectral data are in agreement with the drawn structure (Scheme 3).

The same methodology was applied for the synthesis of flibanserin, also known as "female viagra", which is the first approved medication for treating HSDD in women and is classified as a multifunctional serotonin agonist antagonist. ${ }^{14,15}$ Our synthesis of flibanserin commenced with 1-benzyl-1,4dihydroquinoxaline-2,3-dione $36,{ }^{16}$ which was reacted with known chloride $37^{17}$ under the basic condition in DMF to give the desired product $\mathbf{3 8}$ in good yield. Compound $\mathbf{3 8}$ was subjected for the decarbonylative cyclization under the optimized condition to afford the product 39 in 59\% yield. Finally, the benzyl group was deprotected using trifluorome- 
Scheme 3. Late-Stage Functionalization of Hunanamycin A

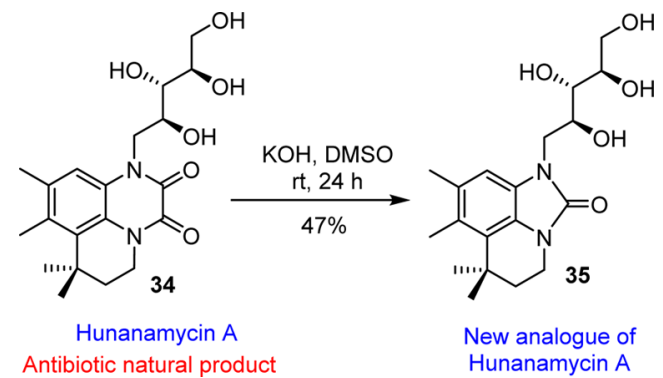

thanesulfonic acid in toluene under microwave irradiation, ${ }^{8 \mathrm{~b}, 18}$ which gave flibanserin in excellent yield (Scheme 4). The final product was isolated as $\mathrm{HCl}$ salt, and all of the spectral data are in agreement with the published data. ${ }^{15 \mathrm{c}}$

\section{Scheme 4. Synthesis of Flibanserin through Ring} Contraction
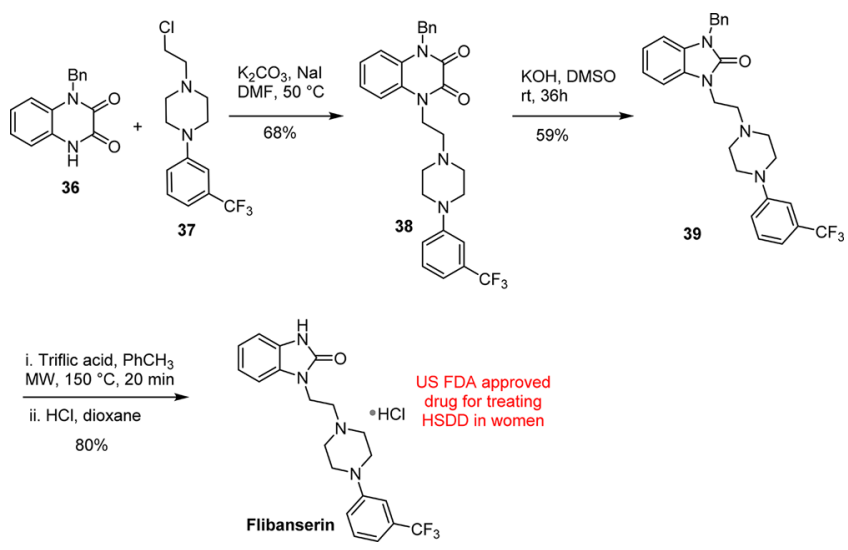

\section{CONCLUSIONS}

We have developed a mild and new protocol for the synthesis of benzimidazol-2-ones from quinoxalinediones through decarbonylation. The present methodology can be an addition to the toolbox to prepare benzimidazolones, and it will be useful in medicinal chemistry, particularly, late-stage functionalization of natural products, drug scaffolds, or an intermediate containing quinoxaline-2,3-diones. As direct application of this method, we have successfully developed a new route for the synthesis of recently approved drug flibanserin and a urea analogue of antibiotic natural product hunanamycin A. Later application demonstrates the utility of the present method in late-stage functionalization.

\section{ASSOCIATED CONTENT}

\section{S Supporting Information}

The Supporting Information is available free of charge on the ACS Publications website at DOI: 10.1021/acsomega.7b00819.

Further experimental procedure and NMR spectrum of the products (PDF)

\section{AUTHOR INFORMATION}

\section{Corresponding Author}

*E-mail: ds.reddy@ncl.res.in. Phone: +91-20-2590 2445 (D.S.R.).

\section{ORCID}

D. Srinivasa Reddy: 0000-0003-3270-315X

Notes

The authors declare no competing financial interest.

\section{ACKNOWLEDGMENTS}

We thank the CSIR (ORIGIN: CSC0108 and NICE-P: CSC0109 programs under XII Five Year Plan) for the financial support. R.D.S. thanks UGC for the award of a research fellowship.

\section{REFERENCES}

(1) (a) Omura, H.; Kawai, M.; Shima, A.; Iwata, Y.; Ito, F.; Masuda, T.; Ohta, A.; Makita, N.; Omoto, K.; Sugimoto, H.; Kikuchi, A.; Iwata, H.; Ando, K. The SAR studies of novel CB2 selective agonists, benzimidazolone derivatives. Bioorg. Med. Chem. Lett. 2008, 18, 3310. (b) Palmer, W. S.; Poncet-Montange, G.; Liu, G.; Petrocchi, A.; Reyna, N.; Subramanian, G.; Theroff, J.; Yau, A.; Kost-Alimova, M.; Bardenhagen, J. P.; Leo, E.; Shepard, H. E.; Tieu, T. N.; Shi, X.; Zhan, Y.; Zhao, S.; Barton, M. C.; Draetta, G.; Toniatti, C.; Jones, P.; Do, M. G.; Andersen, J. N. Structure-guided design of IACS-9571, a selective high-affinity dual TRIM24-BRPF1 bromodomain inhibitor. J. Med. Chem. 2016, 59, 1440. (c) Liu, W. G.; Lau, F.; Liu, K.; Wood, H. B.; Zhou, G. C.; Chen, Y. L.; Li, Y.; Akiyama, T. E.; Castriota, G.; Einstein, M.; Wang, C.; McCann, M. E.; Doebber, T. W.; Wu, M.; Chang, C. H.; McNamara, L.; McKeever, B.; Mosley, R. T.; Berger, J. P.; Meinke, P. T. Benzimidazolones: A new class of selective peroxisome proliferator-activated receptor $\gamma(\operatorname{PPAR} \gamma)$ modulators. J. Med. Chem. 2011, 54, 8541. (d) Howard, H. R.; Sarges, R.; Siegel, T. W.; Beyer, T. A. Synthesis and aldose reductase inhibitory activity of substituted 2(1H)-benzimidazolone- and oxindole-1-acetic acids. Eur. J. Med. Chem. 1992, 27, 779. (e) Barreca, M. L.; Rao, A.; De Luca, L.; Zappalà, M.; Monforte, A.-M.; Maga, G.; Pannecouque, C.; Balzarini, J.; De Clercq, E.; Chimirri, A.; Monforte, P. Computational strategies in discovering novel non-nucleoside inhibitors of HIV-1 RT. J. Med. Chem. 2005, 48, 3433. (f) Monforte, A.-M.; Logoteta, P.; Ferro, S.; De Luca, L.; Iraci, N.; Maga, G.; De Clercq, E.; Pannecouque, C.; Chimirri, A. Design, synthesis, and structure-activity relationships of 1,3-dihydrobenzimidazol-2-one analogues as anti-HIV agents. Bioorg. Med. Chem. 2009, 17, 5962. (g) Patel, V.; Bhatt, N.; Bhatt, P.; Joshi, H. D. Synthesis and pharmacological evaluation of novel 1-(piperidin-4yl)-1H-benzo[d]imidazol-2(3H)-one derivatives as potential antimicrobial agents. Med. Chem. Res. 2014, 23, 2133. (h) Omura, H.; Kawai, M.; Shima, A.; Iwata, Y.; Ito, F.; Masuda, T.; Ohta, A.; Makita, N.; Omoto, K.; Sugimoto, H.; Kikuchi, A.; Iwata, H.; Ando, K. The SAR studies of novel $\mathrm{CB} 2$ selective agonists, benzimidazolone derivatives. Bioorg. Med. Chem. Lett. 2008, 18, 3310. (i) Satoh, A.; Sagara, T.; Sakoh, H.; Hashimoto, M.; Nakashima, H.; Kato, T.; Goto, Y.; Mizutani, S.; Azuma-Kanoh, T.; Tani, T.; Okuda, S.; Okamoto, O.; Ozaki, S.; Iwasawa, Y.; Ohta, H.; Kawamoto, H. Identification of an orally active opioid receptor-like 1 (ORL1) receptor antagonist 4-\{3[(2R)-2,3-Dihydroxypropyl]-2-oxo-2,3-dihydro-1H-benzimidazol-1yl\}-1-[(1S,3S,4R)-spiro[bicyclo[2.2.1] heptane-2,1'-cyclopropan]-3ylmethyl]piperidine as clinical candidate. J. Med. Chem. 2009, 52, 4091. (j) Lütnant, I.; Schepmann, D.; Wünsch, B. Benzimidazolone bioisosteres of potent GluN2B selective NMDA receptor antagonists. Eur. J. Med. Chem. 2016, 116, 136. (k) Gribkoff, V. K.; Champigny, G.; Barbry, P.; Dworetzky, S. I.; Meanwell, N. A.; Lazdunski, M. The substituted benzimidazolone NS004 is an opener of the cystic fibrosis chloride channel. J. Biol. Chem. 1994, 269, 10983. (1) Guillaume, M. Expeditious process improvement for the synthesis of RWJ-333966. Org. Process Res. Dev. 2006, 10, 1227. (m) Li, Q.; Li, T.; Woods, K. W.; Gu, W.-Z.; Cohen, J.; Stoll, V. S.; Galicia, T.; Hutchins, C.; Frost, D.; Rosenberg, S. H.; Sham, H. L. Benzimidazolones and indoles as nonthiol farnesyltransferase inhibitors based on tipifarnib scaffold: synthesis and activity. Bioorg. Med. Chem. Lett. 2005, 15, 2918. 
(2) (a) Richards, D. M.; Brogden, R. N.; Heel, R. C.; Speight, T. M.; Avery, G. S. Oxatomide. Drugs 1984, 27, 210. (b) Dhanuka, I.; Simon, J. A. Flibanserin for the treatment of hypoactive sexual desire disorder in premenopausal women. Expert Opin. Pharmacother. 2015, 16, 2523.

(3) (a) Hammach, A.; Barbosa, A.; Gaenzler, F. C.; Fadra, T.; Goldberg, D.; Hao, M.-H.; Kroe, R. R.; Liu, P.; Qian, K. C.; Ralph, M.; Sarko, C.; Soleymanzadeh, F.; Moss, N. Discovery and design of benzimidazolone based inhibitors of p38 MAP kinase. Bioorg. Med. Chem. Lett. 2006, 16, 6316. (b) Gustin, D. J.; Sehon, C. A.; Wei, J.; Cai, H.; Meduna, S. P.; Khatuya, H.; Sun, S.; Gu, Y.; Jiang, W.; Thurmond, R. L.; Karlsson, L.; Edwards, J. P. Discovery and SAR studies of a novel series of noncovalent cathepsin $\mathrm{S}$ inhibitors. Bioorg. Med. Chem. Lett. 2005, 15, 1687. (c) Monforte, A.-M.; Logoteta, P.; De Luca, L.; Iraci, N.; Ferro, S.; Maga, G.; De Clercq, E.; Pannecouque, C.; Chimirri, A. Novel 1,3-dihydro-benzimidazol-2ones and their analogues as potent non-nucleoside HIV-1 reverse transcriptase inhibitors. Bioorg. Med. Chem. 2010, 18, 1702.

(4) (a) Ernst, J. B.; Tay, N. E. S.; Jui, N. T.; Buchwald, S. L. Regioselective synthesis of benzimidazolones via cascade $\mathrm{C}-\mathrm{N}$ coupling of monosubstituted ureas. Org. Lett. 2014, 16, 3844. (b) McLaughlin, M.; Palucki, M.; Davies, I. W. Efficient access to cyclic ureas via pd-catalyzed cyclization. Org. Lett. 2006, 8, 3311.

(5) (a) Diao, X.; Wang, Y.; Jiang, Y.; Ma, D. Assembly of substituted $1 \mathrm{H}$-Benzimidazoles and 1,3-Dihydrobenzimidazol-2-ones via $\mathrm{CuI} / \mathrm{l}$ Proline catalyzed coupling of aqueous ammonia with 2-Iodoacetanilides and 2-Iodophenylcarbamates. J. Org. Chem. 2009, 74, 7974. (b) Barbero, N.; Carril, M.; SanMartin, R.; Domínguez, E. Coppercatalyzed intramolecular $\mathrm{N}$-arylation of ureas in water: a novel entry to benzoimidazolones. Tetrahedron 2008, 64, 7283.

(6) Yu, J.; Gao, C.; Song, Z.; Yang, H.; Fu, H. Metal-free oxidative $\mathrm{C}-\mathrm{H}$ amidation of $N, N^{\prime}$-diarylureas with $\mathrm{PhI}(\mathrm{OAc}) 2$ : Synthesis of benzimidazol-2-one derivatives. Eur. J. Org. Chem. 2015, 5869.

(7) (a) Zhang, H.-Z.; Cui, S.-F.; Nagarajan, S.; Rasheed, S.; Cai, G.$\mathrm{X}$.; Zhou, C.-H. A unique one-pot reaction via $\mathrm{C}-\mathrm{C}$ cleavage from aminomethylene benzimidazoles to access benzimidazolones with wide potentiality. Tetrahedron Lett. 2014, 55, 4105. (b) Mamedov, V. A.; Zhukova, N. A.; Zamaletdinova, A. I.; Beschastnova, T. N.; Kadyrova, M. S.; Rizvanov, I. K.; Syakaev, V. V.; Latypov, S. K. Reaction for the synthesis of Benzimidazol-2-ones, Imidazo[5,4-b]-, and Imidazo[4,5c]pyridin-2-ones via the rearrangement of quinoxalin-2-ones and their aza analogues when exposed to enamines. J. Org. Chem. 2014, 79, 9161.

(8) (a) Yuan, Y.; Thomé, I.; Kim, S. H.; Chen, D.; Beyer, A.; Bonnamour, J.; Zuidema, E.; Chang, S.; Bolm, C. Dimethyl sulfoxide/ Potassium hydroxide: A Superbase for the transition metal-free preparation of cross-coupling products. Adv. Synth. Catal. 2010, 352, 2892. (b) Beyer, A.; Reucher, C. M. M.; Bolm, C. Potassium hydroxide/Dimethyl sulfoxide promoted intramolecular cyclization for the synthesis of benzimidazol-2-ones. Org. Lett. 2011, 13, 2876. (c) Thomé, I.; Bolm, C. Transition-metal-free intramolecular Narylations. Org. Lett. 2012, 14, 1892. (d) Beyer, A.; Buendia, J.; Bolm, C. Transition-metal-free synthesis of oxindoles by Potassium tertbutoxide-promoted intramolecular $\alpha$-arylation. Org. Lett. 2012, 14, 3948. (e) Thomé, I.; Besson, C.; Kleine, T.; Bolm, C. Base-catalyzed synthesis of substituted indazoles under mild, transition-metal-free conditions. Angew. Chem., Int. Ed. 2013, 52, 7509.

(9) Quinoxalinediones are prepared by heating with 1,2-diaminoaryl compounds with diethyloxalate or oxalic acid/HCl. See refs: (a) Xie, D.; Wang, Y.; Xie, J.; Lu, J.; Cui, J.; Zhang, M.; Fu, L.; Wang, Y. Quinoxaline-2,3-diones: potential d-amino acid oxidase (DAAO) inhibitors. Med. Chem. Res. 2014, 23, 4977. (b) Nakhi, S.; Rahman, M. S.; Kishore, R.; Meda, C. L. T.; Deora, G. S.; Parsa, K. V. L.; Pal, M. Pyrrolo[2,3-b]quinoxalines as inhibitors of firefly luciferase: Their $\mathrm{Cu}$ mediated synthesis and evaluation as false positives in a reporter gene assay. Bioorg. Med. Chem. Lett. 2012, 22, 6433.

(10) Sutar, R. L.; Kumar, V.; Shingare, R. D.; Thorat, S.; Gonnade, R.; Reddy, D. S. A General approach to $N$-heterocyclic carbenes with a fused tetracyclic core: Ligands for Suzuki-Miyaura cross-coupling reaction. Eur. J. Org. Chem. 2014, 4482.
(11) Reddy, D. S.; Shingare, R. D.; Velayudham, R. Novel tricyclic compounds and process for preparation thereof. U.S. Patent 20160152616 A1, 2016.

(12) Shingare, R. D.; Velayudham, R.; Gawade, J. R.; Reddy, D. S. First total synthesis of Hunanamycin A. Org. Lett. 2013, 15, 4556.

(13) Hu, Y.; Wang, K.; MacMillan, J. B. Hunanamycin A, an antibiotic from a marine-derived Bacillus hunanensis. Org. Lett. 2013, 15,390 .

(14) Stahl, S. M. Mechanism of action of Flibanserin, A multifunctional serotonin agonist and antagonist (MSAA), in hypoactive sexual desire disorder. CNS Spectrums 2015, 20, 1.

(15) See, previous synthesis of Flibanserin: (a) Bietti, G.; Borsini, F.; Turconi, M.; Giraldo, E.; Bignotti, M. For treatment of central nervous system disorders. U.S. Patent 5,576,318, 1996. (b) Mohan, R. D.; Reddy, P. K.; Reddy, B. V. Process for the preparation of Flibanserin involving novel intermediates. WO2010128516 A2, 2010. (c) Yang, F.; Wu, C.; Li, Z.; Tian, G.; Wu, J.; Zhu, F.; Zhang, J.; He, Y.; Shen, J. A Facile route of synthesis for making Flibanserin. Org. Process Res. Dev. 2016, 20, 1576.

(16) Jarrar, A. A.; Fataftah, Z. A. Photolysis of some quinoxaline-1,4dioxides. Tetrahedron 1977, 33, 2127.

(17) Xueong, X. Preparation method of Flibanserin. CN104926734 A, 2015.

(18) Rombouts, F.; Franken, D.; Martínez-Lamenca, C.; Braeken, M.; Zavattaro, C.; Chen, J.; Trabanco, A. A. Microwave-assisted $N$ debenzylation of amides with triflic acid. Tetrahedron Lett. 2010, 51, 4815. 